\title{
Several Issues on “Ke-Cheng Si-Zheng”
}

\author{
Zhiqiang Zhou' ${ }^{1}$, Li Guo ${ }^{*}$, Qiang Liu ${ }^{2}$ \\ ${ }^{1}$ College of Chemistry, Chemical Engineering and Resource Utilization, Northeast Forestry University, Harbin, China \\ ${ }^{2}$ Faculty of Science, University of Bristol, Bristol, UK \\ Email: ${ }^{\star}$ guoli_nefu@nefu.edu.cn
}

How to cite this paper: Zhou, Z. Q., Guo, L., \& Liu, Q. (2019). Several Issues on "Ke-Cheng Si-Zheng". Creative Education, 10, 3402-3409.

https://doi.org/10.4236/ce.2019.1013262

Received: November 22, 2019

Accepted: December 17, 2019

Published: December 20, 2019

Copyright $\odot 2019$ by author(s) and Scientific Research Publishing Inc. This work is licensed under the Creative Commons Attribution International License (CC BY 4.0).

http://creativecommons.org/licenses/by/4.0/ (c) (i) Open Access

\begin{abstract}
An education and teaching reform called "Ke-Cheng Si-Zheng" is rising and booming in Chinese higher education to incorporate ideological \& political education into all courses. "Ke-Cheng" means courses, "Si-Zheng" means ideological \& political education. "Ke-Cheng Si-Zheng" means that, all courses shall carry ideological \& political education, and ideological \& political education shall be embodied in all courses. The reform aims at establishing a comprehensive three-dimensional system of ideological \& political education with all staff, whole process and all courses involved in. "Si-Zheng Ke-Cheng" (meaning ideological \& political theoretical courses) carries out explicit ideological \& political education using clear-cut instruction, while other courses carry out implicit ideological \& political education in the form of recessive penetration to embody, digest and sublimate what the former has done. All kinds of courses shall go in the same direction as the "Si-Zheng Ke-Cheng" concerning ideological \& political education, and a synergistic effect shall be realized. This paper discusses on the connotation of "Ke-Cheng Si-Zheng", the relationship between "Si-Zheng Ke-Cheng" and "Ke-Cheng Si-Zheng", and several issues for keeping the right direction of "Ke-Cheng Si-Zheng" reform.
\end{abstract}

\section{Keywords}

Ke-Cheng Si-Zheng, Si-Zheng Ke-Cheng, Ideological and Political Education, Teaching Reform

\section{Introduction}

The Communist Party of China (hereinafter referred to as "the Party") has always attached great importance to the ideological \& political work. It is the good tradition and political advantage of the Party providing strong ideological guarantee and spiritual strength for the consolidation, development and prosperity of the cause of socialism with Chinese characteristics. Ideological \& political educa- 
tion has been an essential part and a distinctive characteristic of Chinese higher education.

Traditionally, the explicit ideological \& political theoretical courses (called "Si-Zheng Ke-Cheng" in Chinese) were the main, even the sole, channel for ideological \& political education. They are core theoretical courses in higher education mainly introducing Marxism, Leninism, Mao Zedong Thought, Deng Xiaoping Theory, the Important Thought of Three Represents, Scientific View of Development, and Xi Jinping Thought on Socialism with Chinese Characteristics for A New Era. But, the traditional "Si-Zheng Ke-Cheng" has long been "fighting alone" and borne alone the important task of ideological \& political education, either actively or passively. In the new era, traditional "Si-Zheng Ke-Cheng" has encountered new challenges and problems. The blending and collision of diversified cultures and values imported by globalization inevitably lead to the formation and spread of various social trends of thought, which produce great impacts on the ideology, value orientation, faith and belief, and behavior orientation of people, especially young students (Zheng, 2015; Zhao, 2010; Wu \& Wan, 2019; Qin \& Jin, 2019; Guo, 2018b; Zhang \& Zhang, 2016). The single approach and monotonous form of traditional "Si-Zheng Ke-Cheng" instruction may weaken its attractiveness, educational effectiveness and value-guiding force. Some students may have misunderstandings of "Si-Zheng Ke-Cheng" instruction and even extreme views on it, thinking that the courses are just moral preaching and force-feeding of old ideas that constrain their freedom of thought. It encounters difficulties to cultivate and practice the social core values as mainstream thought in college students. Ideological \& political education needs to be strengthened, the educational effectiveness needs to be improved, and corresponding education and teaching reform is urgently needed.

"Ke-Cheng Si-Zheng" emerges and rises at this right moment to establish a comprehensive system of ideological \& political education.

\section{The Connotation of "Ke-Cheng Si-Zheng"}

"Ke-Cheng" means courses, "Si-Zheng" means ideological \& political education, and "Ke-Cheng Si-Zheng" means that all courses shall carry ideological \& political education, and ideological \& political education shall be embodied in all courses (Qiu, 2017; Qiu, 2018; Zhao, 2019; Gao \& Zong, 2017a; Dong, 2018; Gao \& Zong, 2017b; Zhang, 2018; Yang, 2018).

"Ke-Cheng Si-Zheng" is not a certain course or the adding of one or more courses. It is a teaching reform and innovation. It means to run Marxist theory through the whole process of teaching and reform, to deeply explore the ideological \& political education elements contained in all courses, and to give full play to the ideological \& political educational function of each course. Each course shall play the role of ideological \& political education at the same time of fulfilling its own specific mission of imparting knowledge. Ideological \& political education shall be incorporated into all courses to establish a three-dimensional 
system of ideological \& political education involving all staff, whole process and all courses. All kinds of courses shall go in the same direction with the "Si-Zheng Ke-Cheng" concerning ideological \& political education. "Si-Zheng Ke-Cheng" works as the "main channel" of ideological \& political education, and other courses work as "microcirculations". "Si-Zheng Ke-Cheng" carries out explicit ideological \& political education using clear-cut instruction, while other courses carry out implicit ideological \& political education in the form of recessive penetration to embody, digest and sublimate what the former has done. And then, a synergistic effect shall be realized.

In this way, a comprehensive system of ideological and political education shall be formed, and a three-dimensional "Da Si-Zheng (meaning big Si-Zheng, comprehensive/all-around ideological \& political education)" involving all staff, whole process and all courses shall be established.

\section{The Relationship between "Si-Zheng Ke-Cheng" and "Ke-Cheng Si-Zheng"}

People need to figure out the right relationship between "Si-Zheng Ke-Cheng" and "Ke-Cheng Si-Zheng". Xi Jinping's important address at the National Conference on Ideological and Political Work of Colleges and Universities 2016-"We should make good use of this main channel of classroom teaching, ideological \& political theoretical courses should be further strengthened while being continually improved; ...; each other course should fulfill its all-round obligation, and all kinds of courses should go in the same direction with ideological and political theoretical courses to form a synergistic effect; ..."-needs to be correctly understood.

\section{About "main channel":}

The main channel distinguishes classroom teaching from non-classroom teaching, such as practical teaching etc. Ideological \& political theoretical courses (Si-Zheng Ke-Cheng) are the main channel of moral education (i.e. ideological \& political education), and other kinds of courses are the main channel of intellectual education, physical education, aesthetic education and etc., respectively. Each "education" has its own main channel. For example, the main channel of college students' ideological \& political education should be the ideological \& political theoretical courses, while that of expertise education should be the specialty-based courses.

\section{About "... further strengthened while being continually improved ...":}

It means that, ideological \& political theoretical courses (Si-Zheng Ke-Cheng) should be further improved and strengthened, and the main channel status of "Si-Zheng Ke-Cheng" in the ideological \& political education of college students should be further consolidated.

About "all-round obligation, ... the same direction, ... a synergistic effect":

It means that, other courses should also bear the corresponding moral education responsibility instead of just staying by. As for moral education, "Si-Zheng Ke-Cheng" is the main channel, and other courses are microcirculations. Both 
the two extreme situations of "the main channel overflowing while the microcirculations idling" and "the microcirculations replacing the main channel" should be prevented. Synergistic effect can be realized only when "Si-Zheng Ke-Cheng", working as the main channel, carry out explicit ideological \& political education; and other courses, working as the microcirculation, carry out implicit ideological \& political education to embody, digest and sublimate what the former has done.

"Si-Zheng Ke-Cheng" is explicit courses set up for the purpose of ideological \& political education using clear-cut instruction. "Ke-Cheng Si-Zheng" takes the implicit way to penetrate ideological \& political education utilizing all courses either specialized, general or literal. The roles of "Ke-Cheng Si-Zheng" and "Si-Zheng Ke-Cheng" designated in related national documents are as follows. The Basic Requirements for Ideological and Political Theoretical Courses Teaching in Colleges and Universities in the New Era issued by the Ministry of Education in April 2018 (The Website of the Central People's Government of the People's Republic of China, 2018a) clearly pointed out the role of "Si-Zheng Ke-Cheng" at the beginning: ideological \& political theoretical courses undertake the task of systematic Marxist theoretical education for college students; they are the important battle field for consolidating the guiding position of Marxism in the ideological field of colleges and for adhering to the right direction of socialist education; they are the main channel and core courses for fully implementing the Party's educational policy and the fundamental task of cultivating qualified talents; and they are the soul courses for strengthening and improving the ideological \& political work and realizing the connotative development of higher education. The Implementation Program for Improving the Quality of Ideological and Political Work in Colleges and Universities issued by the Ministry of Education in 2017 (The Website of the National Center for Schooling Development Programme, The Ministry of Education of the People's Republic of China, 2017) pointed out that: we shall vigorously promote the classroom teaching reform towards "Ke-Cheng Si-Zheng", and realize the organic unity of ideological \& political education and knowledge system education by optimizing curriculum, revising reaching materials, improving teaching design, strengthening teaching management, combing the ideological \& political education elements and functions contained in the specialty-based courses and integrating them into classroom teaching. The Some Opinions on Strengthening the Course Construction of "Situation and Policy" in Colleges and Universities in the New Era issued by the Ministry of Education in 2018 (The Website of the Central People's Government of the People's Republic of China, 2018b) pointed out that: colleges and universities should set up optional courses such as Situation and Policy, perfect the curricula system of ideological \& political theoretical education, and give full play to "Ke-Cheng Si-Zheng".

From the descriptions in the above documents, it can be concluded that, "Si-Zheng Ke-Cheng" courses are the core and soul courses, the main channel of 
college students' ideological and political education, and the advantage of socialist higher education. "Ke-Cheng Si-Zheng" is an educational practice, whereof, all staff, whole process and all courses are involved in, the ideological \& political education elements and functions contained in each course are deeply explored and given full play, and the resonance of knowledge instruction and moral education with the same frequency is realized. As for moral education, "Si-Zheng Ke-Cheng" is the main channel while "Ke-Cheng Si-Zheng" is the microcirculations for digesting and sublimating what the former teaches.

\section{The Booming of "Ke-Cheng Si-Zheng" Teaching Reform and Correct Implementation of It}

Along with the issuances of Implementation Program for Improving the Quality of Ideological and Political Work in Colleges and Universities and Some Opinions on Strengthening the Course Construction of "Situation and Policy" in Colleges and Universities in the New Era by the Ministry of Education in 2018, "Ke-Cheng Si-Zheng" began to generalize and boom nationwide. As of the end of 2018, nearly all schools, colleges and universities of higher education had initiated the teaching reform of "Ke-Cheng Si-Zheng", even as a political task. And now, it is in full swing. The party committee of each college is the leadership body of "Ke-Cheng Si-Zheng" reform and construction, must treat it as an important political task, and must do this work with high sense of political responsibility. Educational staff has been motivated to actively participate in the reform. Relevant research programs of different levels have been set up and funds have been provided. With the rising of "Ke-Cheng Si-Zheng", relevant research gets booming. Zhou et al. (Zhou, Guo, \& Liu, 2019) listed the volumes of literatures concerning “Ke-Cheng Si-Zheng (课程思政)" since 2014 (the year when "Ke-Cheng Si-Zheng" had been put forward) and as of Sep. 16, 2019 searched in CNKI (China National Knowledge Infrastructure) as shown in Table 1. The big volumes of literatures concerning "Ke-Cheng Si-Zheng" and especially their rapid increase in the past three years fully reflect the booming of "Ke-Cheng Si-Zheng" and educators' enthusiasm in it and acceptance of it.

"Ke-Cheng Si-Zheng" is a complicated systematical project. Scientific design, planning, evaluation and management are essential. "Ke-Cheng Si-Zheng" construction and reform need continuous exploring, deepening and perfecting. Not only the teaching level and effect should be improved, but also experience and practice that can be used for reference should be formed. It requires people to conclude and learn from the successful cases, to correctly understand the right connotation of "Ke-Cheng Si-Zheng", to strengthen research, to put heads together, to associate with reality, to actively explore, and to make timely summaries. Guided by the important address of Xi Jinping at the National Conference on Ideological and Political Work of Colleges and Universities 2016 and guided by related national documents, a complete scientific system should be formed to establish the synergistic goal, to enhance teachers' awareness of education, to 
Table 1. Literatures concerning "Ke-Cheng Si-Zheng".

\begin{tabular}{|c|c|c|c|c|}
\hline \multirow{2}{*}{ Source } & \multicolumn{4}{|c|}{ With the term of “Ke-Cheng Si-Zheng (课程思政)" in } \\
\hline & Title & Topic & Abstract & Keywords \\
\hline \multirow[t]{7}{*}{ Journals } & Total: 1177 & Total: 3368 & Total: 1448 & Total: 1101 \\
\hline & 2019 (as of Sep. 16): 808 & 2019 (as of Sep. 16): 2127 & 2019 (as of Sep. 16): 977 & 2019 (as of Sep. 16): 760 \\
\hline & 2018: 333 & 2018: 736 & 2018: 409 & 2018: 311 \\
\hline & $2017: 36$ & 2017: 209 & 2017: 58 & 2017: 30 \\
\hline & 2016: 0 & 2016: 131 & 2016: 3 & 2016: 0 \\
\hline & 2015: 0 & 2015: 90 & 2015: 0 & 2015: 0 \\
\hline & 2014: 0 & 2014: 75 & 2014: 1 & 2014: 0 \\
\hline Dissertations & Total: 4 & Total: 66 & Total: 25 & Total: 6 \\
\hline \multirow{6}{*}{$\begin{array}{c}\text { (Master's and } \\
\text { Doctor's) }\end{array}$} & 2019 (as of Sep. 16): 3 & 2019 (as of Sep. 16): 27 & 2019 (as of Sep. 16): 16 & 2019 (as of Sep. 16): 4 \\
\hline & 2018: 1 & 2018: 11 & 2018: 8 & 2018: 2 \\
\hline & 2017: 0 & 2017: 12 & 2017: 1 & 2017: 0 \\
\hline & 2016: 0 & 2016: 5 & 2016: 0 & 2016: 0 \\
\hline & 2015: 0 & 2015: 8 & 2015: 0 & 2015: 0 \\
\hline & 2014: 0 & 2014: 3 & 2014: 0 & 2014: 0 \\
\hline \multirow[t]{7}{*}{ Proceedings } & Total: 6 & Total: 14 & Total: 16 & Total: 6 \\
\hline & 2019 (as of Sep. 16): 3 & 2019 (as of Sep. 16): 3 & 2019 (as of Sep. 16): 11 & 2019 (as of Sep. 16): 4 \\
\hline & 2018: 3 & 2018: 5 & 2018: 5 & 2018: 2 \\
\hline & 2017: 0 & 2017: 1 & 2017: 0 & 2017: 0 \\
\hline & 2016: 0 & 2016: 2 & 2016: 0 & 2016: 0 \\
\hline & 2015: 0 & 2015: 3 & 2015: 0 & 2015: 0 \\
\hline & 2014: 0 & 2014: 0 & 2014: 0 & 2014: 0 \\
\hline \multirow[t]{8}{*}{ Newspapers } & Total: 59 & Total: 139 & & \\
\hline & 2019 (as of Sep. 16): & 2019 (as of Sep. 16): & & \\
\hline & 16 & 58 & & \\
\hline & 2018: 24 & 2018: 45 & & \\
\hline & 2017: 15 & $2017: 25$ & & \\
\hline & 2016: 4 & 2016: 7 & & \\
\hline & 2015: 0 & 2015: 4 & & \\
\hline & 2014: 0 & 2014: 0 & & \\
\hline
\end{tabular}

systematically scheme the construction plan, to make flexible teaching, and to conduct scientific evaluation. In a word, as for implementing "Ke-Cheng Si-Zheng" teaching reform well, people should calm down, come down to the earth, look for the truth and be practical, resist fame-fishing, and scientifically think and plan.

\section{Bad Utilization of "Ke-Cheng Si-Zheng"}

Some people, even some institutions regard "Ke-Cheng Si-Zheng" as a fashion and rush into it to "seize a first chance" and to make self-branding. Following the successful launch of "CHINA SERIES" courses in colleges and universities in Shanghai, some colleges have also created their own so-called "brand" courses by 
imitation, making "Ke-Cheng Si-Zheng" become a label and leading to formalism and vulgarization. Some colleges just simply simulate and copy the successful cases, just emphasize the form but despise the content. And so, "Ke-Cheng Si-Zheng" just becomes an image project, and a great deal of manpower and material resources are wasted with no practical effect. And some people, even some institutions utilize "Ke-Cheng Si-Zheng" to seek fame and gain, for example, to acquire research projects, funds, awards, and etc. These phenomena exit, but the quantity or proportion cannot be accurately counted. People must be vigilant against bad utilization of "Ke-Cheng Si-Zheng".

\section{Conclusion}

"Ke-Cheng Si-Zheng" is an innovative education and teaching reform in the new era for establishing a comprehensive three-dimensional system of ideological \& political education with all staff, whole process and all courses involved in. It is of profound connotation and important practical significance, and positive outcomes can be expected. "Ke-Cheng Si-Zheng" is a complicated systematical project. For implementing it well, scientific design, planning, evaluation and management are essential. People should calm down, come down to the earth, look for the truth and be practical, resist fame-fishing, and scientifically think and plan. People must be vigilant against bad utilization of "Ke-Cheng Si-Zheng".

\section{Acknowledgements}

This work was financially supported by the Higher Education Teaching Reform Project in Heilongjiang Province (SJGY20170129, SJGY20180021), the "Ke-Cheng Si-Zheng" Demonstration Courses Construction Program of Northeast Forestry University (Li Guo), and the Fundamental Research Funds for the Central Universities (2572015CB28).

\section{Conflicts of Interest}

The authors declare no conflicts of interest regarding the publication of this paper.

\section{References}

Dong, Y. (2018). On the Value Connotation of Development from "Si-Zheng Ke-Cheng" to "Ke-Cheng Si-Zheng". Ideological and Political Education Research, 34, 90-92.

Gao, D. Y., \& Zong, A. D. (2017a). From "Si-Zheng Ke-Cheng” to "Ke-Cheng Si-Zheng": To Construct the Course System of Ideological and Political Education in Colleges and Universities from the Strategic Height. China Higher Education, 1, 43-46.

Gao, D. Y., \& Zong, A. D. (2017b). "Ke-Cheng Si-Zheng": The Inevitable Choice for Effectively Giving Full Play to the Role of the Main Channel of Classroom Education. Leading Journal of Ideological and Political Education, 1, 31-34.

Guo, Y. L. (2018). New Expression of the Current Social Trends of Thought in China and Related Response. Scientific Socialism, 5, 140-142. 
Qin, Z. D., \& Jin, S. Y. (2019). The Threat of Erroneous Social Trends of Thought to the Security of China's Mainstream Ideology and Its Governance. Ideological and Political Education Research, 1, 81-86.

Qiu, R. F. (2018). Theoretical Interpretation of the Synergistic Progress of "Ke-Cheng Si-Zheng" and "Si-Zheng Ke-Cheng". Studies in Ideological Education, 4, 109-113.

Qiu, W. G. (2017). The Value Implication and Generation Path of "Ke-Cheng Si-Zheng". Ideological \& Theoretical Education, 9, 10-14.

The Website of the Central People's Government of the People's Republic of China (2018a). Basic Requirements for Ideological and Political Theoretical Courses Teaching in Colleges and Universities in the New Era.

http://www.gov.cn/xinwen/2018-04/26/content_5286036.htm

The Website of the Central People's Government of the People's Republic of China (2018b). Some Opinions on Strengthening the Course Construction of "Situation and Policy" in Colleges and Universities in the New Era.

http://www.gov.cn/xinwen/2018-04/27/content_5286310.htm

The Website of the National Center for Schooling Development Programme, The Ministry of Education of the People's Republic of China (2017). Implementation Program for Improving the Quality of Ideological and Political Work in Colleges and Universities. http://www.csdp.edu.cn/article/3314.html

Wu, L. S., \& Wan, M. R. (2019). Impact and Guidance: Diversified Social Trends of Thought and Youth's Spiritual Life Development. Ideological and Political Education Research, 3, 59-64.

Yang, H. (2018). From "Course of Ideological and Political Education" to "Courses for Ideological and Political Education". Journal of Yangzhou University (Higher Education Research Edition), 22, 98-104.

Zhang, J., \& Zhang, J. H. (2016). Analysis of the Influence of the Current Social Trends of Thought on China's Mainstream Ideology. Theoretical Investigation, 1, 73-76.

Zhang, Z. G. (2018). The Logical Clue of Synergistic Progress of "Si-Zheng Ke-Cheng" and "Ke-Cheng Si-Zheng". Study of Ideological and Political Course, 8, 16-19.

Zhao, J. W. (2019). Connotation, Idea, Problems, and Countermeasures of "Ke-Cheng Si-Zheng". Journal of Hubei University of Economics, 17, 114-119.

Zhao, Y. (2010). To Correctly Understand and Scientifically Guide the Social Trends of Thought. People's Daily, August 12, 007.

Zheng, Y. X. (2015). To Scientifically Guide the Social Trends of Thought and Promote the Ideological and Political Education in Colleges and Universities. Zhongguo Jiaoyu Bao, April 23, 011.

Zhou, Z. Q., Guo, L., \& Liu, Q. (2019). “Ke-Cheng Si-Zheng”-An Innovative Educational Reform Rising in Chinese Higher Education. Creative Education, 10, 2473-2483. https://doi.org/10.4236/ce.2019.1011175 